\title{
Enterprise Resource Planning: An Open Source System
}

\author{
Anand Kr. Shukla \\ Assistant .Prof \\ IICA Dept Invertis University, Bareilly
}

\author{
Ajay Indian \\ Associate Prof \\ IICA Dept Invertis University,Bareilly
}

\begin{abstract}
Over the last decade, ERP systems have assumed great importance in the IT sector because it offers myriad benefits which include sales forecasting, centralization of data, order tracking, decision support, competitive edge, and many more. To achieve all such kinds of benefits, FOSS (Free and Open Size Systems) are gaining importance in the IT industries. The main objective of this research paper is to study how well Open ERP Systems can be implemented on SMEs.
\end{abstract}

This research paper aims to throw light on how ERP systems can be implemented on SME'S(Small and Mid Size Enterprises, carefully analyzing three things; one :The model of Free and Open Source Systems has been refined over the years, how that change will affect the future development of ERPs ,two : The business environment for SME's has become more complex through globalization, resulting in a need to develop more advanced technology, three :challenges faced by the ERP vendors while developing such an ERP for SMEs.

\section{Keywords}

SMEs, FOSS

\section{INTRODUCTION}

\section{BACKDROP}

The backbone of this research paper lies on the ERP systems and FOSS(free and open source system).Due to the advancement of technologies in the IT sector, ERP systems have been widely used because of their benefits which include efficiency, cost saving, flexibility and majorly competitive advantage. The most popular proprietary ERP vendors include:

- Oracle

- Microsoft

- SAP

- The SAGE Group

- PeopleSoft

The dominants of open source ERP market are Adempiere , Compiere, ERP5, Open ERP and Blue ERP. It has been observed that the big vendor dominated market of ERP applications will start adopting non -proprietary technology.

Open source ERPs are gaining an upper hand over proprietary applications and SMEs are using Open Source ERPs because they are easily affordable to SMEs.

1). Open source ERP vendors offer affordable price for the development of the systems.

2). Open source ERPs are suitable for SMEs as well as large organizations.

\section{METHODOLOGY}

To choose an open source ERP system for an organization, two studies have to be done-

1). Theoretical research.

\section{2). Empirical research.}

The theoretical research includes a comprehensive review of academic work to be done to build the model that will form the basis of the empirical study. The theoretical research identifies selection criteria for SMEs and large organizations. The empirical research serves as a guiding model for application of Open Source ERP to SMES.

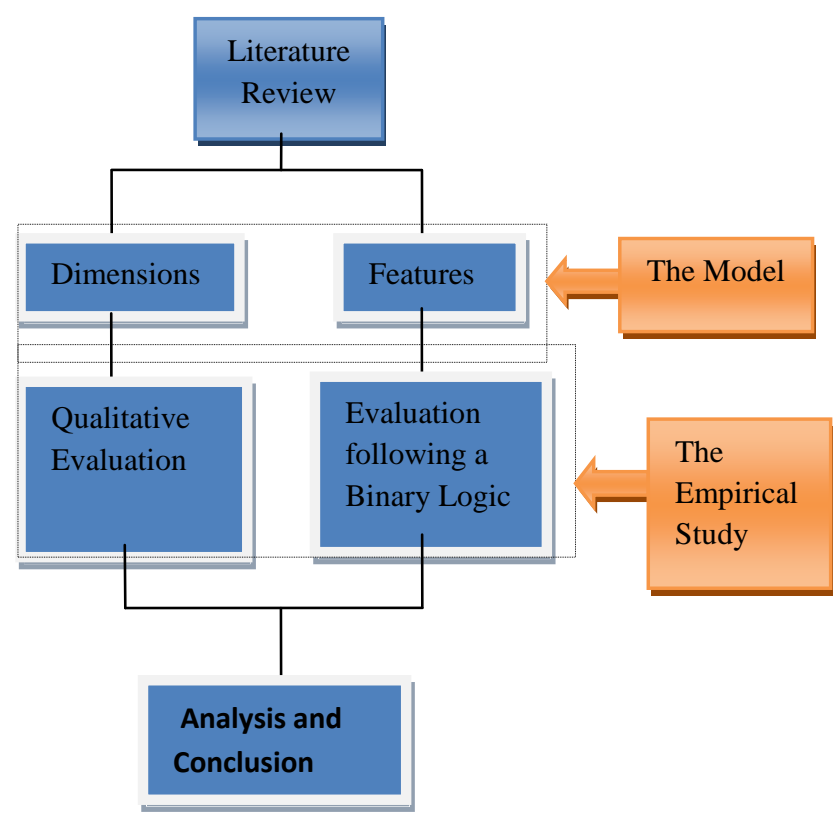

Fig: 1 The methodology

\section{ERP SYSTEMS AS AN OPEN SOURCE SOFTWARE}

In general, Open Source refers to any program or software whose source code and some other rights are made available for use or modification by others, under a software license that meets the Open Source definition of the Open Source Initiative (OSI) or that is in the public domain. Open source software is usually developed as a public collaboration and made freely available. The origin of open source software can be traced back to the 1950's. According to a study carried out by the Standish group (2000) discussing proprietary ERPs implementation, $28 \%$ of the implementations respect the budget, the time and while satisfying the needs of the enterprise, $49 \%$ are a failure in terms of budget, time and functionalities, and $23 \%$ are abandoned before they finish. Mentioning this fact, the numerous benefits of Open Source ERP are as follows:

- Low cost of implementation

- $\quad$ Free license

- Services for free

- No pre-sales cost hence free

- Few days of implementation 
- Take comparatively less time in training

- Available source code

- High level customization

- Flexibility to the customer in choosing vendor

- High security

- Responsive

\section{STATUS OF OPEN SOURCE ERP}

Source forge (hosts open source projects) is the world's largest Open Source Software development website. A research was made in September 2007 and a similar one was made in November. The search showed that 336 Open Source ERPs were registered in September and by November there was a rise in registration of Open Source ERPs by 20 (within 10 weeks).This clearly shows how much importance companies are giving to Open Source ERPs.

The other way of calculating the importance of Open Source ERPs is by counting the number of downloads of the software as such. The consultants of the ERP sector made recommendations to the SMEs for downloading the software and giving it a look. The following table describes about downloads from six open source ERPs projects. It shows the interest towards Open Source ERP software has increased owing to the huge amounts of downloads by the companies

Table 1: for Downloads of Open Source ERP's

\begin{tabular}{|l|l|l|l|l|l|l|}
\hline $\begin{array}{l}\text { OPEN } \\
\text { SOUR } \\
\text { ERP }\end{array}$ & $\begin{array}{l}\text { COMP } \\
\text { IERE }\end{array}$ & $\begin{array}{l}\text { OPENB } \\
\text { RA VO }\end{array}$ & $\begin{array}{l}\text { OPEN } \\
\text { TAPS }\end{array}$ & $\begin{array}{l}\text { FACTUR } \\
\text { ALUX }\end{array}$ & $\begin{array}{l}\text { WEB } \\
\text { ERP }\end{array}$ & $\begin{array}{l}\text { TINY } \\
\text { ERP }\end{array}$ \\
\hline $\begin{array}{l}\text { Novem } \\
\text { ber 27 }\end{array}$ & $\begin{array}{l}1,296,0 \\
98\end{array}$ & 401,262 & $\begin{array}{l}311,96 \\
4\end{array}$ & 235,897 & $\begin{array}{l}149,0 \\
10\end{array}$ & 21,116 \\
\hline $\begin{array}{l}\text { Septem } \\
\text { ber 13 }\end{array}$ & $\begin{array}{l}1,267,1 \\
60\end{array}$ & 300,716 & $\begin{array}{l}284,42 \\
9\end{array}$ & 231,031 & $\begin{array}{l}138,0 \\
64\end{array}$ & 6,953 \\
\hline $\begin{array}{l}\text { Dowon } \\
\text { loads } \\
\text { during } \\
10 \\
\text { weeks }\end{array}$ & $+28,938$ & $+100,546$ & $+27,535$ & $+4,866$ & $+10,94$ & $+14,16$ \\
& & & & & 6 & 3 \\
\hline $\begin{array}{l}\text { Start of } \\
\text { the } \\
\text { project }\end{array}$ & $8 / 6 /$ & $9 / 3 / 2006$ & $10 / 8 /$ & $1 / 9 / 2006$ & $7 / 1 /$ & $25 / 3 / 2005$ \\
\hline
\end{tabular}

\section{FREE AND OPEN SOURCE SYSTEM OSS ERP: ERP FOR SMEs}

Because of the high complexity associated with large corporations' business processes, OSS ERP might never be suitable for them. Instead, SMEs are more suitable candidates for it. This observation has been verified by surveying OSS ERP packages available in open source repositories. Almost all of them are geared towards the SMEs market. Unlike large companies, SMEs can more easily adapt themselves to everchanging business environments. This business agility is one of the major strengths that SMEs have.

There is another reason why OSS ERP development is currently viable. The maturity of OSS in general has made it possible that many components, i.e., building blocks, of an ERP system can be open-sourced, e.g., DBMS, OS, and web servers. Equally companies relying on OSS component based developments will face a similar situation, but arguably there is a better basis for this co-dependent development amongst projects in the OSS community.

\section{DISCUSSION}

This chapter summarizes the findings that we've been discussing so far.

It is a well known fact that ERPs have high cost which prevents it from spreading to SMEs. Most of the ERPs are difficult to be customized by end-users thus it prevents developers to further innovatively improve the system.

- Today's Open Source ERP systems are suitable for SMEs.

- Today's Open Source ERP systems are suitable for large organizations.

\section{For large organizations:}

- Large organizations value the aspects related to the flexibility and process improvement that the ERP software is supposed to bring into the organization more than SMEs (e.g. increased organizational flexibility, process improvement and improved innovation capabilities)

\section{CONCLUSION AND FUTURE RESEARCH}

Several needs came out of this study, and here is aquick summary of them:

For large organizations:

- Large organizations value the aspects related to the flexibility and process improvement that the ERP software is supposed to bring into the organization more than SMEs (e.g. increased organizational flexibility, process improvement and improved innovation capabilities).

- Internationality of the software and customer and supplier needs

- Stability and history of the supplier. This includes also the current market position of the vendor.

- Upgradeability and improvement in ERP packages, including stability of the product and functionality as well as improved innovation capabilities.

- Short implementation time.

- Good support, this includes implementation support

- Integration.

- Scalability abstract as the conclusion. A conclusion might elaborate on the importance of the work or suggest applications.

\section{For SMEs:}

- Adaptability and flexibility of the software. This includes technical upgradeability and incorporation of latest technologies.

- A short implementation time.

- Lower costs.

- Fit with business procedures.

- User-friendliness of the system.

- Focus on product characteristics such as the functionality and quality of the products and services, rather than on 
characteristics of the ERP supplier of the product.

- Integration or in other words the possibility of the product to interface with other applications.

- Good support from supplier and training.

- Domain knowledge of suppliers.

\section{For large organizations}

- Regarding the fact that large organizations value the flexibility that the ERP software is supposed to bring into the organization, it can be said that all three systems can satisfy this need.

- When it comes to the internationality of the software, all three systems support multicurrency and multiple languages. However a gap was found in the accounting support of the three systems. Indeed while most of the systems have an inbuilt support for the accounting principles used in large and developed countries, they lack support for the accounting principles of less industrial countries. This can be a large issue for international and large public organizations.

- Regarding history, stability and market position of the vendor, relatively all open source don't have a long history, many are recent players that haven't been in the market for many years.

\section{For SMEs}

- Customization and fit to business procedures: very small organizations many times don't even afford the extra cost of specific development needed on occasions. For this reason, their choice of an ERP system will go for the one that can be easily configured and maintained without the need for development skills. All three systems can answer this need. Open ERP in particular, who is based on a very modular and flexible technology can offer a very good choice for a smal/mediuml organization. It can adapt easily to the company's business processes through its integrated BPM module, which doesn't require any specific development. This is also possible with OpenBravo however this comes at the expense of specific development (there is no BPM included in OpenBravo). OpenERP seems to offer the most appropriate choice regarding the "fit to business procedures" aspect.

- Cost: Open Source ERPs are intended to be available to organizations with the least of amount of cost possible, and regarding this aspect all three systems are practically similar, devoted to remain purely Open Source. For example, in the OpenERP case, very small organizations which do not want to invest neither in the integrating specific developments nor in the maintenance of their server, can invest in the hosted solutions offered by OpenERP at very competitive prices.

- Ergonomics and user friendliness: both OpenBravo and OpenERP seem to offer a very good choice in this category, even though OpenERP takes the prize in this category. OpenBravo made the choice to offer a web interface since its split from Compiere in 2002. This web interface is available for all the functional modules that this OpenSource ERP system offers, for free and under the Mozilla Public License (MPL). On the other hand, with Adempiere, this possibility is not totally in place yet, and the work being carried out by some specialized integrators is still in its early stages and not completely reliable.
- Regarding domain knowledge of suppliers, both OpenERP and OpenBravo seemed to be more ready than Adempiere Regarding common needs between large organizations and SMEs:

When it comes to upgradeability and improvement in ERP packages, it can be said that all three can meet this need. When it comes to scalability, all three systems present some limitations. There are still some doubts about the ability of those systems to handle big volumes or requests because of the use of high level of abstraction.

\section{REFERENCES}

[1] M. Aladwani, 'Change Management Strategies for Successful ERP Implementation', Business Process Management Journal, Vol. 7, No. 3, 2001, pp.266-275

[2] A Gupta, 'Enterprise Resource Planning: the Emerging Organizational Value Systems', Industrial Management \& Data Systems, Vol. 100, No. 3, 2000, pp. 114-18

[3] Baki \& K. Cakar, 'Determining the ERP PackageSelecting Criteria', Business Process Management Journal, Vol. 11, No. 1, 2005, p. 75-86

[4] B.Hecht, 'Choose the Right ERP Software', Datamation, Vol. 43, No. 3, 1997, pp.56-8

[5] E. Bernroider \& S. Koch, 'ERP Selection Process in Midsize and Large

[6] Organizations', Business Process Management Journal, Vol. 7, No. 3, 2001, pp. 251-257

[7] E.M. Shehab, M.W. Sharp, L. Supramaniam \& T.A. Spedding, 'Enterprise Resource

[8] Planning An Integrative Review', Business Process Management Journal, Vol. 10, No. 4, 2004, pp. 359-386

[9] E. Van Stijn \& A. Wensley, 'Organizational Memory and the Completeness of Process Modeling in ERP Systems Some Concerns, Methods and Directions for Future Research', Business Process Management Journal, Vol. 7, No. 3, 2001, pp. 181-194

[10] F. Fui-Hoon Nah, J. Lee-Shang Lau \& J. Kuang, 'Critical Factors for Successful Implementation of Enterprise Systems', Business Process Management Journal, Vol. 7, No. 3, 2001, pp. 285-296

[11] F. Robert Jacobs \& F.C. Weston, Jr., 'Enterprise Resource Planning (ERP)—A Brief

[12] History', Journal of Operations Management, Vol. 25, No. 2, March 2007, pp. 357- 363

[13] Fabien, B. (2008). Forrester : l'adoption de l'Open Source est souvent égoïste (online). generation-nt. Available from : $\quad$ http://www.generation-nt.com/opensourceadoption-europe-amerique-nord-entreprises-etudeforrester-actualite-121081.html (accessed 10/3/2009).

[14] Farber, D. (2004). Six Barriers to Open Source Adoption (online). ZD Net. Available from: http://techupdate.zdnet.com/techupdate/stories/main/Six barriers_to_open_source_adoption.html (accessed $5 / 2 / 2009$ ) 